\title{
Factors Influencing Contraceptives Use among Women in the Juba City of South Sudan
}

\author{
Justin Geno Obwoya, ${ }^{1}$ Joseph K. Wulifan, ${ }^{2}$ and Albino Kalolo $\mathbb{D}^{1,3}$ \\ ${ }^{1}$ Virtual University of Uganda, Kampala, Uganda \\ ${ }^{2}$ School of Business \& Law, Department of Administration \& Management Studies, University for Development Studies, Wa, Ghana \\ ${ }^{3}$ Department of Community Health, St. Francis University College of Health and Allied Sciences, Ifakara, Tanzania
}

Correspondence should be addressed to Albino Kalolo; kaloloa@gmail.com

Received 16 November 2017; Accepted 3 January 2018; Published 31 January 2018

Academic Editor: Sally Guttmacher

Copyright (C) 2018 Justin Geno Obwoya et al. This is an open access article distributed under the Creative Commons Attribution License, which permits unrestricted use, distribution, and reproduction in any medium, provided the original work is properly cited.

\begin{abstract}
Understanding birth control and child spacing methods used by inhabitants of conflict afflicted settings is important in designing interventions to improve uptake of family planning services. In addressing the dearth of knowledge on family planning use in these settings, this study aimed at identifying the influencing factors of contraceptives use among women in the Juba city of South Sudan. Using a population based cross-sectional study, 380 women aged 15-49 years filled a guided questionnaire between April and May in 2015. We collected contraceptive use data and factors influencing family planning uptake. Data analysis was performed using descriptive statistics and binary logistic regression. Lifetime reported contraceptive use stood at $42 \%$ whereas contraceptive use in the last three months was 36\%. Logistic regression revealed attitudes ( $\mathrm{AOR}=1.375,95 \mathrm{CI} 1.246-1.518)$ and parity $(\mathrm{AOR}=1.242,95 \%$ CI 1.000-1.544) as significant determinants of lifetime contraceptive use whereas only attitude $(\mathrm{AOR}=1.348, p<0.001)$ determined contraceptive use in last three months. The findings indicate optimal uptake of family planning and point to the influence of attitudes and parity on contraceptive use. Changing attitudes and embedded sociocultural and political structures influencing attitudes is important to promote contraceptive uptake in these settings.
\end{abstract}

\section{Background}

The sustainable development goals (SDGs) that replaced the Millennium development goals (MDGs) at the end of 2015 aim at promoting universal access to sexual and reproductive health $(\mathrm{SRH})$ services $[1,2]$. One of the main targets to reach the SDGs (3.7 and 5.6) is to promote family planning $[1,3]$. Also, timely achievement of family planning targets is expected to hasten achievement across 5 SDG themes of People, Planet, Prosperity, Peace, and Partnership [3]. Implementation of family planning interventions, however, is context dependent and the countries with stable sociopolitical infrastructure may be better suited to successfully implement the interventions and achieve the goals than their counterparts in conflict afflicted settings. The conflict afflicted settings often have fragile health systems that can hardly support provision of comprehensive SRH [4-6]

Current reports on the global contraceptive prevalence rates and unmet needs for family planning indicate overall gains across countries [1]. Despite the overall gains, indicators of slow progress in contraceptive uptake and reduction in unmet needs or family planning are evident in some sub-Saharan African countries [1]. The situation of family planning uptake and unmet needs for family planning in conflicted afflicted areas in the SSA countries presents a picture of serious overlook by the humanitarian actors. In these settings, available evidence indicates low prevalence rates ranging from $4 \%$ to $16 \%$ and calls for more investment in family planning services for both national and donor country action plans $[7,8]$.

The coverage of contraceptives in eastern Africa stands at $40 \%$ and is expected to grow to $55 \%$ by 2030 [1]. As of the year 2015, in South Sudan, however, only $6.8 \%$ of women of reproductive age use family planning, $2.5 \%$ are using the modern methods of family planning, and $4.1 \%$ are using the traditional methods of family planning $[1,9]$. The low contraceptives uptake South Sudan has been a long-standing national issue with little concrete steps taken to address it 
[10-12]. The two decades of civil war disrupted South Sudan health care system and therefore very little efforts were placed on family planning, even after signing of the comprehensive peace agreement in $2005[6,11]$. Family planning services remained underutilized even where the services were made available [10-12]. The low uptake of contraceptives in South Sudan is likely to expose women to unplanned pregnancies, inadequate child spacing, and increased risks associated with closed spaced pregnancies and child birth. Given the crisis situation, children in poorly spaced births are more prone to malnutrition, diseases, and higher chances of death compared to those that are well spaced [13-16]. This problem is likely to continue if the root causes are not identified and addressed. Understanding the factors that influence access to contraceptive use is key to reducing the disparities that exist in family planning uptake and levels of unmet needs for family planning across settings, including the conflict afflicted countries.

The drivers of family planning uptake are a set of multiple factors that may be complex and difficult to address in real world settings, specifically so in conflict afflicted zones where things happen in an emergency situation [17, 18]. These factors range from individual and social factors, cultural factors, availability, and access factors to factors related to the attributes of the contraceptive methods such as fear of side effects $[12,18,19]$. There is insufficient evidence to explain how these factors interplay to influence contraceptive use in conflict zones of sub-Saharan Africa, such as that of South Sudan.

In view of the relatively low contraceptive use in South Sudan and limited evidence on determinants of use, an assessment of the current contraceptive use levels and factors that determine family planning uptake is timely and appropriate. In this study we aimed to determine the extent of use of modern family planning methods and identify the sociodemographic, sociocognitive, and sociocultural factors influencing the use of family planning methods

\section{Methods}

2.1. Study Settings. The study was conducted in Juba city of South Sudan. We selected Juba city as a study area mainly because of its heterogeneity in terms of population, that is, existence of multiple ethnic groups from different parts of South Sudan. Thus, the information gathered would provide better picture of the determinants of modern contraceptive use and act as a reflection of what might be happening in other states of South Sudan. As of 2010, Juba city had a population of 372,413 people with growth rate of $4.23 \%$ and is made of four "Payams," including Munuki, Kator, Rajaf, and Northern Bari Payams. Due to conflicts in the country, it is difficult to obtain reliable data on population. As of 2015, the total fertility rate in South Sudan stands at 5 children whereas maternal and child mortality rates are recorded at 789 deaths/100,000 live births and 93 deaths/100,000, respectively [20].

2.2. Study Design. This study employed a quantitative crosssectional design and included as respondents the sexually active women aged 15 to 49 years. The study was conducted between March and April in the year 2015. The following steps were followed to implement the study (1) sampling of the study participants, (2) data collection using a structured questionnaire, and (3) analysis of the collected data.

2.3. Sampling Procedures of Study Participants. The sample was calculated using Roasoft formula for sample size estimation [21] which considered 95\% confidence interval (CI) and $5 \%$ margin error and $50 \%$ response rate was used. A total sample of 377 participants was deemed adequate for the study to generate the required evidence. We used a multistage cluster sampling procedures to select participants for the study. From the four Payams, 30 subdivisions referred to as "clusters" were randomly selected. During the selection of the clusters military affiliated areas (military barracks, police barracks, and prisons) and commercial services areas were excluded. The civil conflict that erupted in Juba city in December 2013 leads to restricted access to military affiliated areas [22]. Using a random route approach the data were collected from the households of each of the four clusters until the required sample per clusters was reached.

2.4. Data Collection Instrument and Procedures. We used a structured questionnaire to collect data from the study participants. The questionnaire was constructed based on key issues related to contraceptives use and their determinants including the contextual issues related to the study area and also making reference to existing questionnaires. The questionnaire was organized to include (1) sociodemographic variables of the respondents, (2) use of contraceptive methods, and (3) factors influencing use of contraceptives (such as sociocognitive, sociocultural, and contextual factors). The questionnaire was translated to local language (Juba Arabic) in order to make it understood by the participants. Thereafter, the questionnaires were administered by trained research assistants. During data collection, participants were assured of confidentiality of the information they provided.

\subsection{Variables and Measurements}

2.5.1. Independent Variables. We identified two sets of independent variables, that is, the sociodemographic variables and variables derived from the scales arising from a principal component analysis (PCA) results.

Sociodemographic Variables. The sociodemographic variables considered relevant to the study included age (years), marital status, education, occupation, religion, tribe, and parity. Age was measured as continuous variable (years) and thereafter categorized when deemed important. Marital status of the respondents was measured into categories as married, single, divorced, or cohabiting. We measured education level as no formal education, primary level, secondary level, professional certificate, and university level. The occupation of respondents was measured categorically as retail business, petty trader, civil servant, paid wage, not employed, and others. Religion was measured into following religious affiliations: Catholic, Protestants, Muslims, and others. The 
respondents were allowed to select current religion if they have changed their religious faith. The tribe of the respondent was measured as categorical variables, whereby the most common tribes in Juba city were listed among the possible responses and the minority groups were included among the others.

Knowledge, Attitudes, and Sociocultural Factors. Principal component analysis $[23,24]$ was conducted to extract questionnaire items to latent constructs. A set of items is not necessarily a scale, but only if the items have a similar underlying construct. The extracted latent constructs were used in the development of the three scales. The three scales (knowledge, attitudes, and sociocultural factors) formed the second set of independent variables of the study.

2.5.2. Dependent Variables. There were two dependent variables considered during the analysis of the collected data and these included contraceptives use in life time and contraceptives use in the last three months. We first measured contraceptives use in life time as a yes or no response to a question "Have you ever used a contraceptive." The second level of measurements was contraceptives use in the last three months, also measured by a dichotomous yes or no response to the question "Have you ever any contraceptive in the last three months."

2.6. Ethical Approval and Consent to Participate. We obtained ethical approval from the state Ministry of Health in Central Equatorial Region of South Sudan and permission to conduct the study from the local authority. During data collection, participants were requested to voluntarily participate in the survey and a written consent was obtained from each participant. Participants were also given a chance to object their participation on the study. Confidentiality and protection of the collected information were assured.

2.7. Statistical Analysis. The collected data from the study participants was analyzed descriptively followed by an analytical approach. The descriptive part provided a univariate analysis of the study variables whereas detailed analytical approach determined associations between the independent and dependent variables. Descriptive analysis was performed to get a clear picture of the background information before progressing to the analytical approach. Description of the sample was presented as mean, median, and range percentages displayed as charts or tables. To reduce the items in the questionnaire and obtain scales for independent variables, a factor analysis using a principal component analysis was conducted. Guided by a scree plot, three factors were extracted and included constructs related to knowledge, attitudes, and sociocultural norms. Only items with reliability coefficient greater than $60 \%$ were considered to construct scales [25]. In this study, the scales had reliability coefficient of 0.737 for attitude, 0.617 for sociocultural norms, and 0.606 for knowledge.

Pearson's bivariate correlation was conducted in order to show how dependent (contraceptive use) variables are related to independent (determinants of contraceptive use) variables. Furthermore, binary logistic regression analysis using a backward selection procedure was conducted to obtain the predictors of contraceptive use. Multicollinearity was ruled out, since the variance inflation factor (VIF) of the model was less than 2.0 for all the two dependent variables meaning that there were no signs of multicollinearity. All statistical analyses were completed using SPSS version 17.

\section{Results}

3.1. Sociodemographic Characteristics of the Participants. The study reached a total of 380 women. Fifty-two percent of the participants were in the age group of 25-34 and the mean age of the participants was 29 years. Majority of the participants were Christian (93\%) and married (72\%) and $54.6 \%$ belonged to the Bari speaking ethnic groups (i.e., Kakwa, Bari, Kuku, and Mundari). Sixty-six percent of participants had postprimary level of education, but only $37 \%$ of the women were unemployed. Table 1 provides details on participant characteristics.

3.2. Contraceptive Use. In this study we found that only $42.6 \%$ of the study participants reported using family planning methods in lifetime. Also, we found that $36 \%$ of the respondents used contraceptives methods in the last three months (any method).

3.3. Determinants of Contraceptive Use. Lifetime use of contraceptives was positively correlated with level of education $(r=0.118, p<0.05)$ and positively correlated with occupation $(r=0.115, p<0.05)$. We also found a correlation between lifetime contraceptive use and respondent's parity $(r=0.154, p<0.001)$. Level of knowledge on contraceptives only showed weak significant positive correlation with lifetime contraceptive use $(r=0.213, p<0.01)$. Attitudes of the participants towards contraceptive use were correlated with lifetime contraceptive use $(r=0.419, p<0.01)$. Contraceptive use in the last three months was positively correlated with level of education $(r=0.116, p<0.05)$ and positively correlated with occupation $(r=0.113, p<0.05)$. We also found a correlation between lifetime contraceptive use and respondent's parity $(r=0.148, p<0.001)$. Level of knowledge on contraceptives only showed weak significant positive correlation with lifetime contraceptive use $(r=$ $0.205, p<0.01$ ). Attitudes of the participants towards contraceptive use were correlated with contraceptive use in the last three months $(r=0.984, p<0.01)$ (see Table 2)

Regression analysis revealed that attitudes $(\mathrm{AOR}=1.375$, $95 \mathrm{CI} 1.246-1.518)$ and parity $(\mathrm{AOR}=1.242,95 \% \mathrm{CI}$ 1.000-1.544) were stronger predictors of lifetime contraceptive use in the studied population (see Table 3)

Binary regression analysis revealed that only attitude significantly determined the use of contraceptives in the last three months (AOR $=1.366,95 \%$ CI 1.238-1.507) implying that positive attitude to contraceptives predicted use of contraceptives in the last three months by the respondents (see Table 4). 
TABLE 1: Distribution of the participants by sociodemographic variables $(N=380)$.

\begin{tabular}{|c|c|c|}
\hline Variable & Frequency & Percentage \\
\hline \multicolumn{3}{|l|}{ Age } \\
\hline $18-24$ & 91 & 23.9 \\
\hline $25-34$ & 200 & 52.6 \\
\hline $35-44$ & 80 & 21.1 \\
\hline $45-49$ & 9 & 2.4 \\
\hline \multicolumn{3}{|l|}{ Marital status } \\
\hline Married & 275 & 72.4 \\
\hline Single & 82 & 21.6 \\
\hline Divorced & 20 & 5.3 \\
\hline Cohabiting & 3 & 0.8 \\
\hline \multicolumn{3}{|l|}{ Religion } \\
\hline Catholics & 179 & 47.1 \\
\hline Protestants & 174 & 45.8 \\
\hline Muslim & 24 & 6.3 \\
\hline Others & 3 & 0.8 \\
\hline \multicolumn{3}{|l|}{ Tribe } \\
\hline Bari speaking tribes & 208 & 54.7 \\
\hline Other tribes & 172 & 45.3 \\
\hline \multicolumn{3}{|l|}{ Education level } \\
\hline No formal education & 37 & 9.7 \\
\hline Basic education & 88 & 23.2 \\
\hline Secondary school level & 125 & 32.9 \\
\hline Professional certificate & 42 & 11.1 \\
\hline Diploma or degree & 88 & 23.2 \\
\hline \multicolumn{3}{|l|}{ Occupation of respondents } \\
\hline Small retail business & 50 & 13.2 \\
\hline Petty trader & 48 & 12.6 \\
\hline Civil servant & 83 & 21.8 \\
\hline Paid wage & 38 & 10 \\
\hline Unemployed & 140 & 36.8 \\
\hline \multicolumn{3}{|l|}{ Parity } \\
\hline 1 to 2 children & 144 & 37.9 \\
\hline 3-5 children & 108 & 28.4 \\
\hline More than 5 children & 47 & 12.4 \\
\hline No child & 81 & 21.3 \\
\hline
\end{tabular}

\section{Discussion}

The aim of this study was to determine the factors associated with uptake of modern contraceptives in Juba city. Overall, our study reveals optimal utilization of the contraceptive methods in the study area. In addition, our findings provide information for a better understanding of the factors associated with the use of family planning in a conflict afflicted setting.

In our study we found that $42 \%$ of the study participants reported to have used contraceptives. This finding presents a high rate of family planning uptake compared to $6.8 \%$ reported previously in the South Sudan [9], but it is in concordance with the prevalence rate reported for eastern Africa [1]. This rate can be explained by the fact that the data were collected only in urban settings (Juba city) and at a time when the country was relatively free from conflict. The settings in South Sudan characterized by ongoing conflict and a low income status make it difficult for government institutions to collect accurate data on contraceptive prevalence rate when compared to other countries in the eastern Africa and elsewhere in the continent.

Other studies [12] in the study settings report that the long held notion that families have to be bigger [19] and males have to make decisions on use of contraceptives [8] is fading away. Also, young women are increasingly either overtly or covertly making decision to use family planning methods by themselves [12]. Since this study was only conducted in urban settings of the country where there is high exposure to family planning promotion campaigns and easy access to SRH services, the findings may not be generalized to the whole country in which $83 \%$ of the population is rural. However, future studies may expound more on the factors that have contributed to the changing trends of family planning prevalence in the study area order to promote learning across conflict afflicted settings.

The high prevalence of contraceptive use in a predominantly Christian sample may be a result of pragmatic decision making that results from sufferings experienced by households with large families during civil unrest. During conflict times, the life situation that requires family to move to refugee camps and depend on humanitarian assistance may have been seen as a burden to large families, especially, if there are small children. In such situations, challenging and subverting social and religious norms may be one of the ways to cope with the circumstances [12]. Existing evidence in crisis situation indicates high rate of use of pills, injectables, and condoms to limit child bearing and actually not to space births [7].

The finding that the level of education of the respondent was positively correlated with contraceptive use in the last three months supports existing evidence which indicates direct relationship between education level and use of family planning methods $[17,26]$. Also the results provide a clear picture of the settings where the study was conducted, that is, urban settings with two-thirds of the participants having secondary level of education.

The association demonstrated in this study between contraceptive use and parity is also reported elsewhere [17, 18 , 27]. This finding may not be a new finding in the family planning domain but may have different implications in the conflict afflicted settings. In the South Sudan context, the situation may be that women only opt to use family planning methods when they want to stop child bearing and probably there is a missed opportunity of using family planning methods for birth spacing. Although not explored in our study, this finding may also indicate that there is unmet needs for family planning among the women of child bearing age given the barriers that exist in these settings. Efforts to improve uptake should also be directed to improve the knowledge on the wider advantages of family planning methods and emphasize child spacing as well. Future policy directions on family planning should focus on imparting knowledge on wider benefits of 
TABLE 2: Pearson's correlation analysis to predict relationship between contraceptives use with independent variables $($ sample $N=380)$.

\begin{tabular}{|c|c|c|c|c|c|c|c|c|c|c|c|c|}
\hline $\mathrm{S} / \mathrm{N}$ & Variables & (2) & (3) & (4) & (5) & (6) & (7) & (8) & (9) & (10) & (11) & (12) \\
\hline \multirow{2}{*}{ (1) } & \multirow{2}{*}{ Age } & $-.251^{* *}$ & -0.024 & - & - & - & - & $.134^{* *}$ & - & $.103^{*}$ & - & 0.006 \\
\hline & & & & 0.041 & $.272^{* *}$ & $.214^{* *}$ & 0.081 & & 0.023 & & 0.006 & \\
\hline \multirow{2}{*}{ (2) } & \multirow{2}{*}{ Marital status } & & 0.082 & - & 0.093 & 0.047 & $.363^{* *}$ & -0.04 & $.135^{* *}$ & 0.011 & 0.019 & 0.018 \\
\hline & & & & 0.005 & & & & & & & & \\
\hline \multirow{2}{*}{ (3) } & \multirow{2}{*}{ Religion } & & & - & -0.06 & -0.08 & 0.009 & -0.04 & 0.001 & 0.04 & - & -0.06 \\
\hline & & & & 0.037 & & & & & & & 0.056 & \\
\hline \multirow{2}{*}{ (4) } & \multirow{2}{*}{ Tribe } & & & & -0.03 & -0.04 & - & $.157^{* *}$ & -0.03 & 0.012 & 0 & -0.007 \\
\hline & & & & & & & 0.052 & & & & & \\
\hline \multirow{2}{*}{ (5) } & \multirow{2}{*}{ Education } & & & & & $.162^{* *}$ & 0.029 & - & - & - & $-.118^{*}$ & $-.116^{*}$ \\
\hline & & & & & & & & $.398^{* *}$ & $.269^{* *}$ & 0.065 & & \\
\hline (6) & Occupation & & & & & & $-.116^{*}$ & 0.02 & $.127^{*}$ & 0.036 & $.115^{*}$ & $.113^{*}$ \\
\hline (7) & Parity & & & & & & & 0.02 & $.187^{* *}$ & -0.07 & $.154^{* *}$ & $.148^{* *}$ \\
\hline (8) & Knowledge & & & & & & & & $.427^{* *}$ & $.253^{* *}$ & $.213^{* *}$ & $.205^{* *}$ \\
\hline (9) & Attitude & & & & & & & & & $.142^{* *}$ & $.419^{* *}$ & $.408^{* *}$ \\
\hline (10) & Sociocultural norms & & & & & & & & & & 0.036 & 0.044 \\
\hline (11) & $\begin{array}{l}\text { Ever used contraceptives in } \\
\text { your life? }\end{array}$ & & & & & & & & & & & $.984^{* *}$ \\
\hline (12) & $\begin{array}{l}\text { Ever used contraceptives in } \\
\text { the last three months? }\end{array}$ & & & & & & & & & & & \\
\hline
\end{tabular}

${ }^{* *} p$ value $<0.01 ;{ }^{*} p$ value $<0.05$.

TABLE 3: Binary logistic regression independent variables with contraceptives use in lifetime.

\begin{tabular}{|c|c|c|c|c|c|}
\hline \multirow{2}{*}{ Variables } & \multirow{2}{*}{ COR } & \multirow{2}{*}{$\mathrm{AOR}$} & \multicolumn{2}{|c|}{$95 \% \mathrm{CI}$} & \multirow{2}{*}{$p$ value } \\
\hline & & & Lower & Upper & \\
\hline Age & 1.003 & 1.003 & .964 & 1.043 & 0.897 \\
\hline Marital status & .730 & .730 & .482 & 1.105 & 0.137 \\
\hline Education & .973 & .973 & .791 & 1.196 & 0.792 \\
\hline Occupation & 1.104 & 1.104 & .943 & 1.293 & 0.218 \\
\hline Parity & 1.242 & 1.242 & 1.000 & 1.544 & 0.050 \\
\hline Knowledge & 1.054 & 1.054 & .910 & 1.222 & 0.483 \\
\hline Attitude & 1.375 & 1.375 & 1.246 & 1.518 & 0.000 \\
\hline
\end{tabular}

contraceptives and should target equally the urban and rural population.

The role of positive attitudes in various health related behaviors is well documented [28-30]. We also found that there was a significant association between attitudes and contraceptive use. Our findings extend the role of positive attitudes in enhancing behavioral actions regardless of the settings, that is, conflict free or conflict afflicted. This calls for more theory based and settings-sensitive interventions aiming at emphasizing positive attitudes towards use of contraceptives, also extending to other parts of South Sudan.

The cross-sectional nature of our study limits establishment of causal relationship and therefore interpretation of our findings should be taken with such a caution. Since the crisis is ongoing in the region, this cross-sectional study could not provide a clear picture of all seasons of the crisis. We only interviewed women and the findings could be different if men were also included given the fact that male involvement in reproductive health services is currently emphasized and men have influence on use of family planning methods to their spouses. Also, the findings could be more enriched by qualitative approaches which were not taken aboard in this study and could reveal the role of other factors such as political, socioeconomical, and the wider barriers to contraceptive use.

In conclusion, our study suggests that women in the Juba city of South Sudan are highly aware of the family planning methods and use family planning optimally. Also, women have little understanding on the wider benefits of family planning apart from using family planning methods to stop childbearing. The factors that significantly influence family planning methods use in the study area are parity, age, level of education, and attitudes. The influence of cultural factors may need further follow-up as it did not come clearly in our study. 
TABLE 4: Binary logistic regression independent variables with contraceptives use in the last three months.

\begin{tabular}{|c|c|c|c|c|c|}
\hline \multirow{2}{*}{ Variables } & \multirow{2}{*}{ COR } & \multirow{2}{*}{$\mathrm{AOR}$} & \multicolumn{2}{|c|}{$95 \% \mathrm{CI}$} & \multirow{2}{*}{$p$ value } \\
\hline & & & Lower & Upper & \\
\hline Age & 1.009 & 1.009 & .970 & 1.049 & 0.663 \\
\hline Marital status & .752 & .752 & .498 & 1.135 & 0.175 \\
\hline Education & .974 & .974 & .792 & 1.196 & 0.799 \\
\hline Occupation & 1.108 & 1.108 & .947 & 1.297 & 0.201 \\
\hline Parity & 1.222 & 1.222 & .984 & 1.517 & 0.070 \\
\hline Knowledge & 1.044 & 1.044 & .901 & 1.210 & 0.563 \\
\hline Attitude & 1.366 & 1.366 & 1.238 & 1.507 & 0.000 \\
\hline
\end{tabular}

\section{Conflicts of Interest}

The authors declare that they have no conflicts of interest.

\section{Authors' Contributions}

Justin Geno Obwoya conceived the research idea and participated in the design, coordination of data collection, and drafting of the paper. Joseph K. Wulifan participated in the drafting of the paper. Albino Kalolo participated in designing the research idea, performed the statistical analysis, and participated in proofreading the paper.

\section{Acknowledgments}

The authors are grateful to the Central Equatorial State Authority for providing the permission to conduct the study. Many thanks are due to the women who participated in the study.

\section{References}

[1] United Nations, Trends in Contraceptive Use Worldwide 2015, UN, Department of Economic and Social Affairs, Population Division, 2015.

[2] S. S. Lim, K. Allen, Z. A. Bhutta et al., "Measuring the healthrelated Sustainable Development Goals in 188 countries: a baseline analysis from the Global Burden of Disease Study 2015," The Lancet, vol. 388, pp. 1813-1850, 2016.

[3] E. Starbird, M. Norton, and R. Marcus, "Investing in family planning: Key to achieving the sustainable development goals," Global Health Science and Practice, vol. 4, no. 2, pp. 191-210, 2016.

[4] M. Philips and K. Derderian, "Health in the service of statebuilding in fragile and conflict affected contexts: An additional challenge in the medical-humanitarian environment," Conflict and Health, vol. 9, no. 1, article no. 13, 2015.

[5] L. Lawry, C. Canteli, T. Rabenzanahary, and W. Pramana, "A mixed methods assessment of barriers to maternal, newborn and child health in gogrial west, south Sudan," Reproductive Health, vol. 14, no. 1, pp. 1-13, 2017.

[6] A. Jones, N. Howard, and H. Legido-Quigley, "Feasibility of health systems strengthening in South Sudan: A qualitative study of international practitioner perspectives," BMJ Open, vol. 5, no. 12, Article ID e009296, 2015.

[7] T. McGinn, J. Austin, K. Anfinson et al., "Family planning in conflict: Results of cross-sectional baseline surveys in three
African countries," Conflict and Health, vol. 5, no. 1, article no. 11, 2011.

[8] J. K. Mathe, K. K. Kasonia, and A. K. Maliro, "Barriers to adoption of family planning among women in eastern democratic Republic of Congo," African Journal of Reproductive Health, vol. 15, no. 1, pp. 69-77, 2011.

[9] $\mathrm{MOH}$ and USAID, Family Planning and Reproductive Health in South Sudan, USAID Dollars to Results, 2013.

[10] N. Mugo, A. B. Zwi, J. R. Botfield, and C. Steiner, "Maternal and child health in South Sudan," SAGE Open, vol. 5, no. 2, 2015.

[11] S. Kane, M. Rial, A. Matere, M. Dieleman, J. E. Broerse, and M. Kok, "Gender relations and women's reproductive health in South Sudan," Global Health Action, vol. 9, no. 1, article 33047, 2016.

[12] S. Kane, M. Kok, M. Rial, A. Matere, M. Dieleman, and J. E. Broerse, "Social norms and family planning decisions in South Sudan," BMC Public Health, vol. 16, no. 1, article 1183, 2016.

[13] J. C. King, "The risk of maternal nutritional depletion and poor outcomes increases in early or closely spaced pregnancies," The Journal of Nutrition, vol. 133, supplement 2, pp. 1732S-1736S, 2003.

[14] J. Nassim and F. Sai, "Child spacing: impact on health," Dialogue on Diarrhoea, no. 34, article 3, 1988.

[15] A. Conde-Agudelo, A. Rosas-Bermúdez, and A. C. KafuryGoeta, "Birth spacing and risk of adverse perinatal outcomes: a meta-analysis," The Journal of the American Medical Association, vol. 295, no. 15, pp. 1809-1823, 2006.

[16] A. Whitworth and R. Stephenson, "Birth spacing, sibling rivalry and child mortality in India," Social Science \& Medicine, vol. 55, no. 12, pp. 2107-2119, 2002.

[17] J. K. Wulifan, S. Brenner, A. Jahn, and M. De Allegri, "A scoping review on determinants of unmet need for family planning among women of reproductive age in low and middle income countries," BMC Women's Health, vol. 16, no. 1, article no. 2, 2016.

[18] O. L. Olaitan, "Factors influencing the choice of family planning among couples in South West Nigeria," International Journal of Medicine and Medical Sciences, vol. 3, pp. 227-232, 2011.

[19] K. Elmusharaf, E. Byrne, and D. O’Donovan, "Social and traditional practices and their implications for family planning: A participatory ethnographic study in Renk, South Sudan," Reproductive Health, vol. 14, no. 1, article no. 10, 2017.

[20] The World Bank, Martenal Mortality Ratio South Sudan, 2016, http://data.worldbank.org/indicator/SH.STA.MMRT.

[21] Raosoft INC, "Sample Size Calculator by Raosoft, Inc," 2004, http://www.raosoft.com/samplesize.html.

[22] WIKIPEDIA, "South Sudan Civil War," 2016, https://en.wikipedia.org/wiki/South_Sudanese_Civil_War. 
[23] H. Abdi and L. J. Williams, "Principal component analysis," Wiley Interdisciplinary Reviews: Computational Statistics, vol. 2, no. 4, pp. 433-459, 2010.

[24] I. Jolliffe, Principal Component Analysis, Wiley Online Library, 2002.

[25] A. Field, Discovering Statistics Using SPSS, SAGE Publications, 2005.

[26] P. A. Apanga and M. A. Adam, "Factors influencing the uptake of family planning services in the Talensi District, Ghana," The Pan African Medical Journal, vol. 20, articel 10, 2015.

[27] A. B. Ajong, P. N. Njotang, M. N. Yakum et al., "Determinants of unmet need for family planning among women in Urban Cameroon: A cross sectional survey in the Biyem-Assi Health District, Yaoundé," BMC Women's Health, vol. 16, no. 1, article no. 4, 2016.

[28] I. Ajzen, "The theory of planned behavior," Organizational Behavior and Human Decision Processes, vol. 50, no. 2, pp. 179211, 1991.

[29] A. Kalolo and S. M. Kibusi, "The influence of perceived behaviour control, attitude and empowerment on reported condom use and intention to use condoms among adolescents in rural Tanzania," Reproductive Health, vol. 12, no. 1, article no. 105, 2015.

[30] M. Snyder and D. Kendzierski, "Acting on one's attitudes: Procedures for linking attitude and behavior," Journal of Experimental Social Psychology, vol. 18, no. 2, pp. 165-183, 1982. 


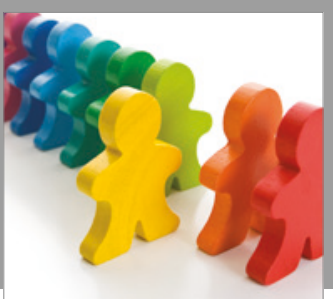

Autism

Research and Treatment
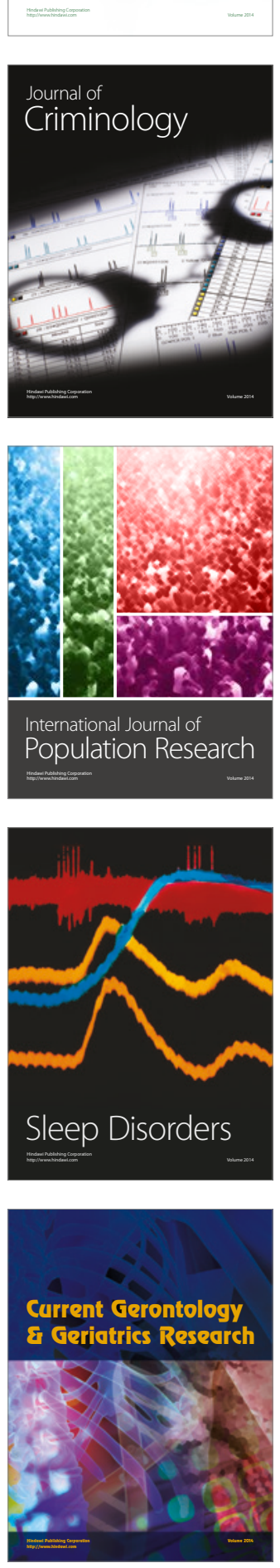

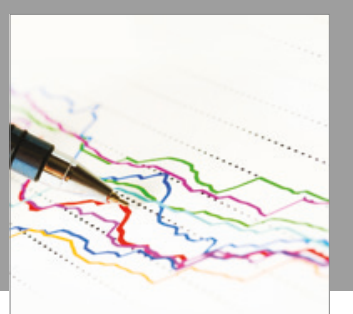

Economics

Research International

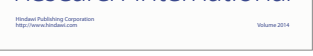

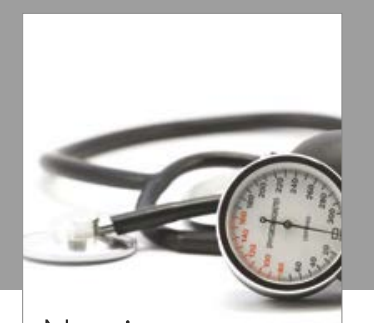

Nursing

Research and Practice

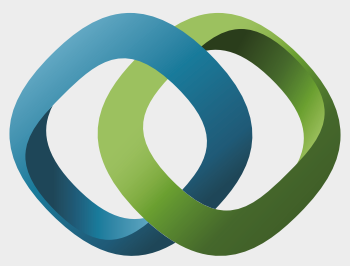

\section{Hindawi}

Submit your manuscripts at

https://www.hindawi.com
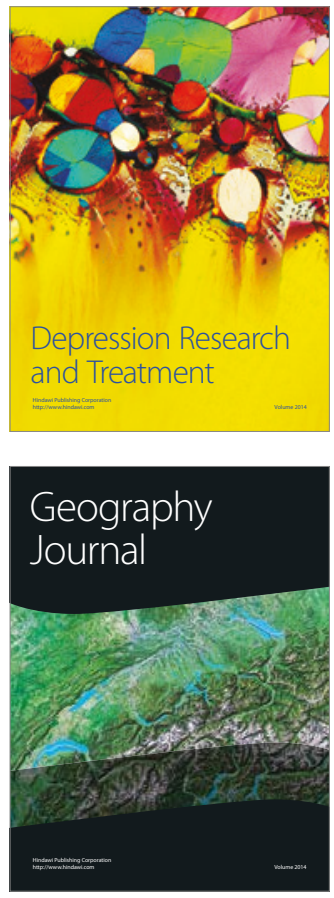
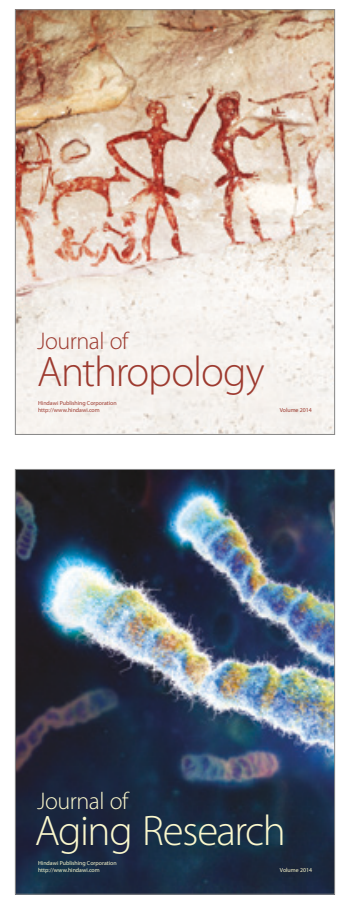
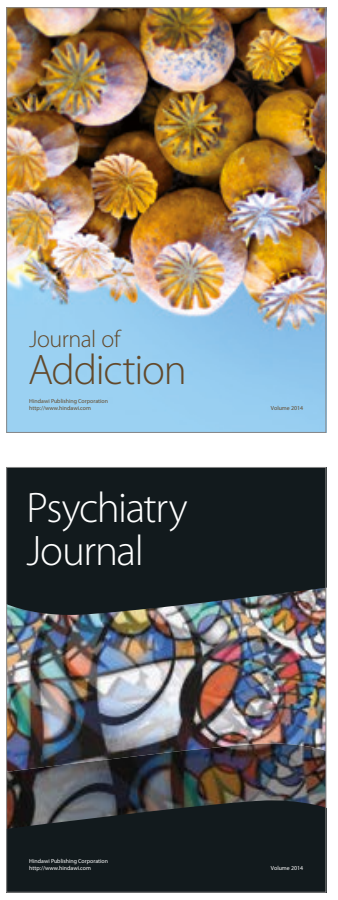

Child Development

Research

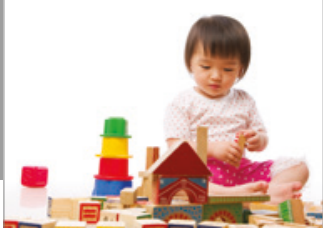

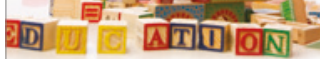
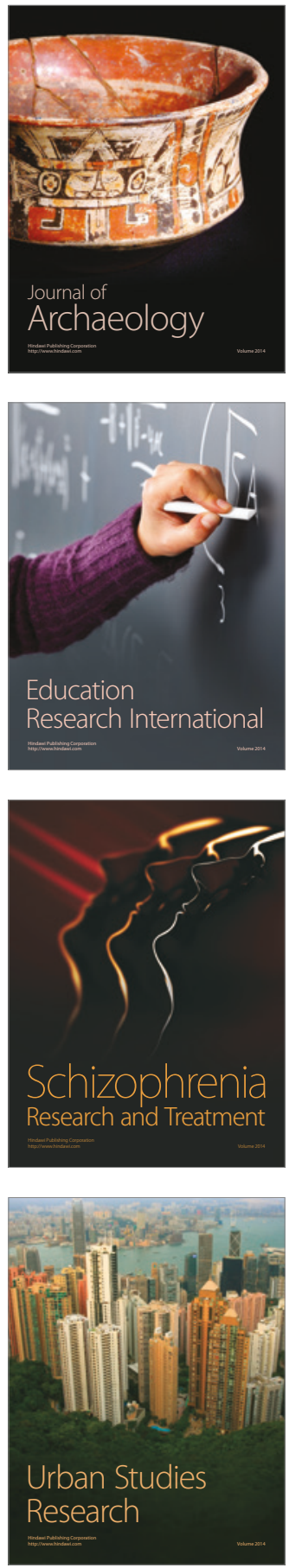